\title{
Effect of Pravastatin on Levels of Filtration Slit Diaphragm Protein and Oxidative Stress in Doxorubicin- Induced Nephrotoxicity
}

\author{
Wesam Kooti ${ }^{1}$, Esrafil Mansouri ${ }^{2 *}$, Mohammad-Ali Assarehzadegan ${ }^{3}$, Fereshteh Nejad-Dehbashi ${ }^{4}$ \\ ${ }^{1}$ Student Research Committee, Kurdistan University of Medical Science, Sanandaj, Iran \\ ${ }^{2}$ Cellular and Molecular Research Center, Department of Anatomical Sciences, Faculty of Medicine, Ahvaz Jundishapur University of \\ Medical Sciences, Ahvaz, Iran \\ ${ }^{3}$ Department of Immunology, Faculty of Medicine, Ahvaz Jundishapur University of Medical Sciences, Ahvaz, Iran \\ ${ }^{4}$ Cellular and Molecular Research Center, Ahvaz Jundishapur University of Medical Sciences, Ahvaz, Iran
}

\begin{abstract}
Introduction: Nephrotoxicity is one of the complications the use of doxorubicin (DXR) which may be caused by the formation of free radicals. The aim of this study was to investigate the effects of pravastatin (PS) on doxorubicin-induced nephrotoxocity. Methods: The rats were divided into control, doxorubicin $(15 \mathrm{mg} / \mathrm{kg}$, i.p.), PS $(20 \mathrm{mg} / \mathrm{kg}$ orally, 5 days prior to DXR injection) + DXR and DXR + PS ( 5 days after DXR injection) groups. At the end of the $20^{\text {th }}$ day, kidneys were removed for evaluation. Podocin mRNA and protein were determined by real-time PCR and Western blotting. Also, the level of tissue's malondialdehyde (MDA), catalase (CAT), Superoxide dismutase (SOD) and glutathione peroxidase (GPx) activities were determined. Results: Adminstration of pravastatin increased $(P<0.005)$ the mRNA and protein expression of podocin and the activities of CAT, SOD and GPx which were decreased in doxorubicin group. Pravastatin also, reduced $(P<0.005)$ the elevated MDA level in doxorubicin group. Conclusion: The present study showed that that pravastatin can improve doxorubicin-induced nephrotoxicity in rats which is associated with the increase in expression of podocin and antioxidant enzymes activities, and decrease in level of MDA.
\end{abstract}

Key words: Pravastatin, Doxorubicin, Nephrotoxicity, Oxidative stress, Podocin

\section{INTRODUCTION}

Cancer is the main cause of mortality in worldwide and claims more than 6 million lives annually. Chemotherapy is not recognized as a safe treatment method because of the side effects of the drugs on the healthy organs. Between the different types of chemotherapeutic drugs, doxorubicin (DXR), which belongs to anthracycline group of antibiotics, is commonly used. ${ }^{1-3}$ DXR has its own dose-dependent cytotoxicity on kidney and other organs similar to the side effects of other anti-cancer drugs. ${ }^{4}$ However the DXR-induced nephrotoxicity mechanism has not exactly been known, it is supposed that the toxicity may be interceded via membrane lipid peroxidation, iron-dependent oxidative injury of biological macromolecules, free radical formation and oxidation of protein ${ }^{5}$ while, the main pathogenic mechanism seem to be the production of toxic reactive oxygen species (ROS). ${ }^{6,7}$ Many in vitro and in vivo researches have shown that metabolites of reactive oxygen containing superoxide anion $\left(0_{2}^{-}\right)$, free radical species, hydroxyl radical $\left(\cdot \mathrm{OH}^{-}\right)$and hydrogen peroxide $\left(\mathrm{H}_{2} \mathrm{O}_{2}\right)$ are main mediators of tissue damage. ${ }^{8}$ It has been reported that the important causative agent of DXR-induced nephrotoxicity is the involvement of oxygen radical-induced damage of membrane
Submission Date: 06-08-2016; Revision Date: 17-11-2016; Accepted Date: 21-11-2016

DOI: 10.5530/ijper.51.1.11 Correspondence: Esrafil Mansouri, Department of Anatomical Science, Cellular and Molecular Research Center, School of Medicine, Ahvaz Jundishapur University of Medical Sciences, Ahvaz, IR Iran.

Address: Esrafil Mansouri, No: 328, Kokab Alley, Professors Quarter, Golestan Blvd, Ahvaz, Khozestan, Iran.

P O. BOX: 6135713977 Phone no: +98-6133738134 E-mail: esrafilmansori@ yahoo.com

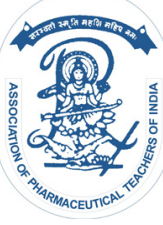

www.ijper.org 
lipids. ${ }^{9}$ According to the available evidence, DXR leads to podocyte damage. ${ }^{10}$ This is probable by using the DXR through generating reactive oxygen. ${ }^{11}$ Injury to podocyte leads to actin cytoskeleton disarrangement and loss of structural entirety that results in foot process effacement and podocyte loss, ultimately leading to progressive nephropathy. Thus, therapies that inhibit podocyte damage and loss will have a main clinical effect in management of glomerular disease. ${ }^{12}$ According to previous studies, statins can directly bind and metabolize reactive oxygen species resulting in reduction of intracellular reactive oxygen species content. ${ }^{13,14}$ In the kidney, statins can prevent mitogenactivated protein kinase and nuclear factor kappa B and also clear off free radicals. Moreover, they prevent the activation of signaling pathways through ROS..$^{15,16}$ Overall, statins may exert benefits against renal damage in experimental conditions of acute or chronic renal function impairment. ${ }^{17}$ Pravastatin (PS), which belongs to the statins group, has been indicated to diminish the incidence of strokes and heart attacks induced by cardiovascular disorders. ${ }^{18}$ In recent studies, the antioxidant and anti-inflammatory properties of pravastatin were recognized. In an in vivo study, the $\mathrm{H}_{2} \mathrm{O}_{2}$-induced endothelial dysfunction was inhibited by pravastatin. ${ }^{19}$ This study, therefore, was focused to evaluate the effect of pravastatin on levels of filtration slit diaphragm protein and oxidative stress in doxorubicin- induced nephrotoxicity

\section{MATERIALS AND METHODS}

\section{Chemicals and Drugs}

Doxorubicin and pravastatin was purchased from Sigma (Sigma Chemical Co. St. Louis, USA). Antibodies were purchased from Santa Cruz (Santa Cruz Biotechnology, USA).

\section{Experimental animals and experimental protocol}

The present study protocol was reviewed and approved by the Ethics Committee of Ahvaz University of Medical Sciences. Male Sprague Dawley rats (150-170 g), were obtained from animals house center of Ahvaz Jundishapur University of Medical Sciences, Ahvaz, Iran. The animals were allowed unrestricted access to water and rat chow. The rats were randomly divided into four groups (6 rats each): Control group; receiving distilled water for 20 days orally, DXR group; receiving single i.p. dose of $15 \mathrm{mg} / \mathrm{kg}$ DOX, PS + DXR group; receiving pravastatin $(20 \mathrm{mg} / \mathrm{kg} /$ day orally) 5 days prior to DXR injection and DXR + PS group; receiving pravastatin $(20 \mathrm{mg} / \mathrm{kg} /$ day orally) 5 days after
DXR injection. Pravastatin sodium, was freshly prepared in distilled water and given to animals. At the end of treatment on $20^{\text {th }}$ day after injection of DXR, The animals were weighed and euthanized. The kidneys were removed, weighed and stored at $-80{ }^{\circ} \mathrm{C}$.

\section{Real-time polymerase chain reaction}

Total RNA was extracted from renal cortex tissues using an RNeasy Plus Mini Kit (Qiagen, USA) according to the manufacturer's instructions. To quantify the expression of mRNA, the real-time SYBR-Green assay was performed as previously described.$^{20}$ Primer sets were as follows:

Podocin forward, 5- tggaagctgaggcacaaaga -3, Podocin reverse, 5- agaatctcagccgccatcct -3 ;

GAPDH forward, 5- tggtctacatgttccagtatgact -3, GAPDH reverse, 5- ccatttgatgttggcgggatctc -3 .

\section{Western blotting}

The renal cortex was homogenized in RIPA buffer (consisting of $0.1 \%$ sodium dodecyl sulfate [SDS], $1 \%$ sodium deoxycholate, $1 \%$ Triton $\mathrm{X}-100,150 \mathrm{mM} \mathrm{NaCl}$, $10 \mathrm{mM}$ EDTA, and $25 \mathrm{mM}$ TrisHCl (pH 7.2) and protease inhibitors using a homogenizer. Then, were centrifuged at $13,000 \times \mathrm{g}$ at $4{ }^{\circ} \mathrm{C}$ for 20 minutes and the supernatants were collected. The protein concentration was determined by Bradford method. A total of $75 \mu \mathrm{g}$ of protein of each sample was separated by $10 \%$ SDSPAGE, electroblotted onto PVDF membrane. The membrane was blocked in 5\% bovine serum albumin in TBS for $2 \mathrm{~h}$, and then incubated with primary antibody (1:200 dilution) of podocin overnight at $4{ }^{\circ} \mathrm{C}$. The membrane was washed with Tris-buffered saline with $0.02 \%$ Tween-20 and incubated with 1:5000 diluted secondary donkey anti-goat IgG-HRP (Santa Cruz Biotechnology) for $1 \mathrm{~h}$ at room temperature. The bound secondary antibody was detected by enhanced chemiluminescence system (Najm Biotech ECL Kit, Iran).

\section{Estimation of lipid peroxidation (Malondialdehyde)}

The kidneys were homogenized in Tris- $\mathrm{HCl}$ buffer, $\mathrm{pH}$ $7.4(10 \mathrm{mM}, \mathrm{pH} 7.4)$ at a concentration of $5 \%(\mathrm{w} / \mathrm{v})$ with a homogenizer (Model silent crusher-M; Heidolph Instruments, Donau, Germany). The homogenates were centrifuged at $10,000 \times \mathrm{g}$ at $4{ }^{\circ} \mathrm{C}$ for $20 \mathrm{~min}$. Levels of malondialdehyde (MDA), a validated index of lipid peroxidation, was estimated colorimetrically by thiobarbituric acid reactive substances (TBARS) as described in previous study. ${ }^{21}$

\section{Determination of antioxidant enzymes activity}

Catalse (CAT). CAT activity was measured according to the method of described in our previous study. ${ }^{22}$ The $0.1 \mathrm{ml}$ 
of the supernatant was pipetted into cuvette containing $1.9 \mathrm{ml}$ of $50 \mathrm{mM}$ phosphate buffer ( $\mathrm{pH} 7.0)$. Reaction was initiated by the addition of $1.0 \mathrm{ml}$ of $30 \%(\mathrm{v} / \mathrm{v})$ hydrogen peroxide $\left(\mathrm{H}_{2} \mathrm{O}_{2}\right)$. Changes in absorbance was measured at $240 \mathrm{~nm}$ from the rate of decomposition of $\mathrm{H}_{2} \mathrm{O}_{2}$ for 30 s. Activity CAT was expressed as unit/ $\mathrm{g}$ tissue.

Superoxide dismutase (SOD). SOD activity was measured by Ransod kit (Randox Labs., Crumlin, UK). In this kit employs xanthine and xanthine oxidase (XOD) to generate superoxide radicals which react with 2(4-iodophenyl)-3-(4-nitrophenol)-5-phenyltetrazolium chloride (I.N.T.) to form a red formazan dye. The SOD activity is then measured by the degree of inhibition of this reaction. One unit of SOD is that which causes a $50 \%$ inhibition of the rate of reduction of INT under the conditions of the assay. The absorbance was measured at $560 \mathrm{~nm}$ and was expressed as unit/ $\mathrm{g}$ tissue. Glutathione peroxidase (GPx). GPx activity was measured by Ransel Kit (Randox Labs., Crumlin, UK). GPx catalyzes the oxidation of glutathione by cumene hydroperoxide. In the presence of glutathione reductase and NADPH, the oxidized Glutathione (GSSG) was immediately converted to the reduced form with a concomitant oxidation of NADPH to $\mathrm{NADP}^{+}$. The decrease in absorbance was measured at $340 \mathrm{~nm}$ and the results were expressed as unit/g tissue.

\section{Statistical Analysis}

All of the data were expressed as mean \pm SD. The data obtained from various groups were statistically analyzed using one way ANOVA, followed by tukey - test. P $<0.05$ was considered statistically significant. All statistical analyses were performed with SPSS for Windows, version 15.0 (SPSS Inc., Chicago, IL, USA).

\section{RESULTS}

\section{Effect of pravastatin on body and kidney weights}

Table 1, displays the mean of body and kidney weight in different groups. DXR treatment significantly decreased body weigh when compared to control $(p<0.01)$ but administration of pravastatin had no notable effect on body weight in PS + DXR and DXR + PS groups compared with DXR group. We didn't find any difference in kidney weight of rats in different groups $(p>0.05)$.

\section{Effect of pravastatin on mRNA and protein expression of podocin}

The mRNA and protein expression of podocin were significantly decreased in DXR group compared with control $(\mathrm{P}<0.001)$. However, pravastatin could signifi-

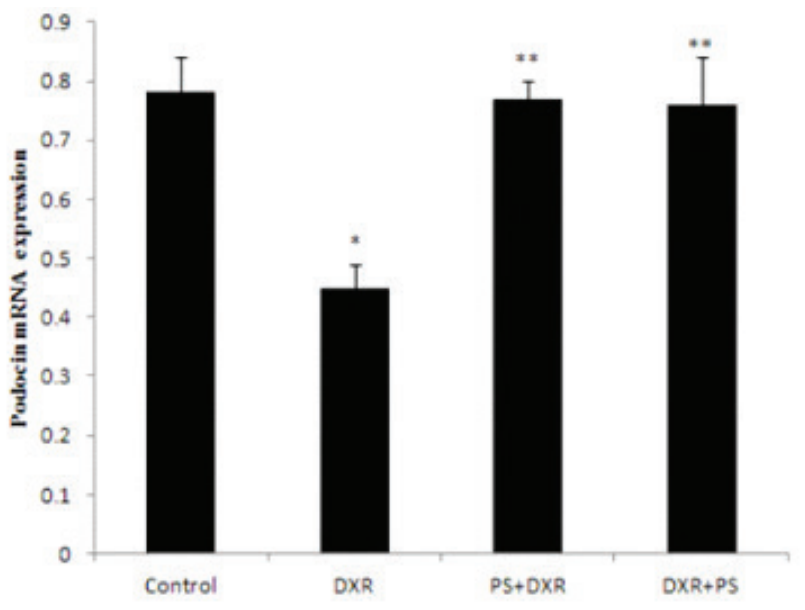

Figure 1: Effects of pravastatin on expression of podocin mRNA in different groups. The values are mean values $\pm S D$, $n=6 .{ }^{*} p<0.001$ compared to control, ${ }^{* *} p<0.001$ compared to doxorubicin (DXR) group. PS (pravastatin), DXR (doxorubicin)

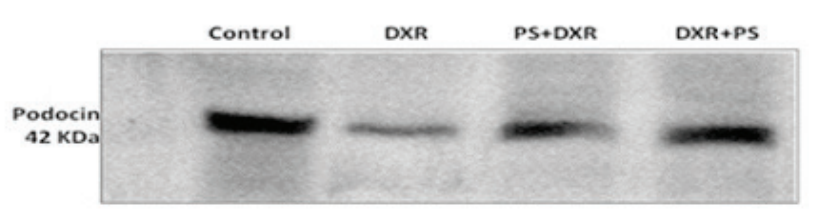

Figure 2: Effects of pravastatin on expression of podocin protein in different groups. Western blotting demonstrated the expression of podocin in control group. The expression of this protein decreased in DXR group, but pravastatin partially restored podocin expression.

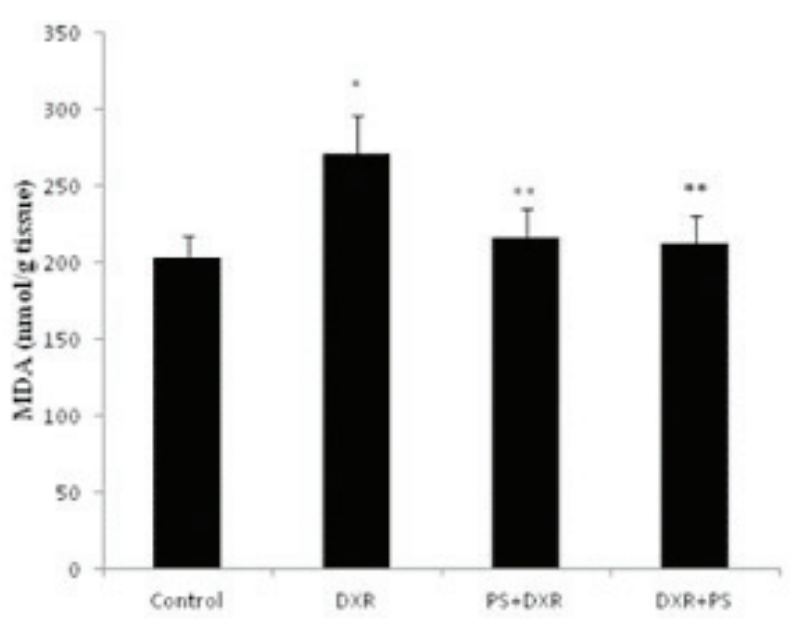

Figure 3: Effects of pravastatin on MDA level in different groups. The values are mean values $\pm S D, n=6$. * $p<0.001$ compared to control, ${ }^{* *} p<0.005$ compared to DXR group.

cantly up-regulate the expressions of podocin in mRNA and protein levels in both groups of PS + DXR and DXR + PS as compared with DXR group $(\mathrm{P}<0.001)$

(Figure. 1 and 2). 


\begin{tabular}{|c|c|c|}
\hline \multicolumn{3}{|c|}{ Table 1: Effects of pravastatin on body and kidney weight in } \\
different groups
\end{tabular}

The values are mean values $\pm \mathrm{SD}, \mathrm{n}=6$. * $p<0.05$ compared to control.

$P S$ (pravastatin), DXR (doxorubicin)

Table 2: Effects of pravastatin on antioxidant enzymes in different groups

\begin{tabular}{|c|c|c|c|}
\hline Groups & CAT (U/g tissue) & SOD (U/g tissue) & GPx (U/g tissue) \\
\hline Control & $44.39 \pm 6.26$ & $787.39 \pm 63.12$ & $32.54 \pm 3.18$ \\
\hline DXR & $16.98 \pm 8^{*}$ & $502.22 \pm 64.80^{*}$ & $15.86 \pm 3.18^{*}$ \\
\hline PS + DXR & $38.21 \pm 4.22^{* *}$ & $749.52 \pm 44.09^{* *}$ & $26.83 \pm 3.59^{\star *}$ \\
\hline DXR +PS & $33.64 \pm 7.26^{* *}$ & $720.58 \pm 26.50^{* *}$ & $27.82 \pm 4.48^{* *}$ \\
\hline
\end{tabular}

The values are mean values $\pm \mathrm{SD}, n=6 .{ }^{*} \mathrm{p}<0.001$ compared to control. $\quad \mathrm{p}<0.01$ compared to DXR group. CAT (catalse), SOD (superoxide dismutase), GPX (glutathione peroxidase), $U$ (unit),

$P S$ (pravastatin), DXR (doxorubicin)

\section{Effect of pravastatin on renal MDA level and}

The effect of pravastatin on DXR-induced elevation of lipid peroxidation (expressed as MDA) level in the kidney tissue homogenate that is shown in Figure 3. Treatment with DXR caused significant increase in MDA content of kidney compared with control $(\mathrm{P}<0.001)$. But treatment with pravastatin in PS + DXR and DXR + PS groups markedly decreased elevated level of MDA in DXR group $(\mathrm{P}<0.005)$.

\section{Effect of pravastatin on renal antioxidant enzymes activity}

The activities of renal enzymes CAT, SOD, GPx are shown in Table 2. The renal CAT, GPx, and GPx activities were significantly lower in DXR group then control group $(\mathrm{P}<0.001)$. Concomitant treatment with pravastatin and DXR in both groups significantly restored these changes in antioxidant enzymes activity when compared to DOX treated group $(\mathrm{P}<0.005)$.

\section{DISCUSSION}

In the present study, our first goal was to demonstrate the intense correlation between DXR-related lipid peroxidation, antioxidant enzymes and expression of podocin mRNA and protein in kidney damage and the protective effects of pravastatin on these parameters. The current study shows that DXR decreased body weight, but had no effect on kidney weight. We also found that pravastatin did not cause any change in body and kidney weight in the groups PS + DXR and DXR + PS when compared to DXR group. The results of current study are in accordance with earlier studies. ${ }^{1,23-25}$ Our findings demonstrated that podocin mRNA and protein were significantly dropped with DXR treatment. Podocin, as a scaffolding protein, is one of protein constituents of the filtration slit diaphragm (SD) which has a key role in maintaining the function and structure of SD. Studies of in vivo and in vitro have supported a scaffolding role of podocin in lipid rafts of foot process membrane in podocytes, that are vital for SD function and structure. ${ }^{26,27}$ In summary, the function and the structure of podocytes are influenced by SD proteins such as podocin. One of momentous interventional strategies for renal damage is inhibition and cure of podocyte injury. The results this study indicated that pravastatin administration up-regulated podocin mRNA and protein expression before and after injecting DXR. Many previous studies showed that statins restored the reduced expressions of podocin in renal injury which these result are consistent with our findings. ${ }^{28,29}$ We have found that DXR increased lipid peroxidation as well as reduced antioxidant enzymes. As mentioned, DXR has toxicity effects for different organs such as kidney. It has been reported that the generation of reactive oxygen and nitrogen species (ROS and RNS), lipid peroxidation and reduced antioxidan levels are the molecular mechanisms responsible for toxicity effects of DXR . ${ }^{30,31}$ In addition, we have observed a decline in MDA levels with an increase in antioxidant enzymes (CAT, SOD 
and GPx) activity in groups which received pravastatin. Statins represent anti-oxidant activities by many mechanisms including increasing the redox regulatory activity of thioredoxin by decreasing in myeloperoxidase and nitric oxide derived oxidants formation, by reducing in the necessary NADPH oxidase expression, by enhancing of the activity of the serum paroxanase I and by increasing level of serum glutathione. ${ }^{32,33}$ However, more studies will be needed to clear the mechanism(s) of the antioxidant effects of pravastatin. Our results are in agreement with previous studie.$^{25}$

\section{CONCLUSION}

These results indicate that pravastatin reverse decreased levels of podocin mRNA and protein which induced by DXR. Also, our data provide more evidence that pravastatin may play an important role as an exogenous antioxidant, which may account, at least in part, for pharmacological action of pravastatin.

\section{ACKNOWLEDGEMENT}

This work was supported by a grant (No.CMRC-86) from Deputy of Research and Technology Development of Ahvaz Jundishapur University of Medical Sciences.

\section{CONFLICTS OF INTEREST}

The authors declare no conflicts of interest.

\section{ABBREVIATIONS USED}

ANOVA: Analysis of variance; CAT: Catalase, DXR: Doxorubicin; EDTA: Ethylenediaminetetraacetic acid; GAPDH: Glyceraldehyde 3-phosphate dehydrogenase; GPx: Glutathione peroxidase; GSSG: Glutathione disulfide; H2O2: Hydrogen peroxide; IgG-HRP: Immunoglobulin G- horseradish peroxidase; INT: 2-(4-iodophenyl)-3-(4-nitrophenyl)-5-phenyl-2H-tetrazolium; MDA: Malondialdehyde; NaCL: Sodium chloride; NADPH: Nicotinamide adenine dinucleotide phosphate; O2- : Superoxide anion; OH- : Hydroxyl radical; PVDF: polyvinylidene difluoride; PS: Pravastatin, RIPA: Radioimmunoprecipitation assay; ROS: Reactive oxygen species; SDS- PAGE: sodium dodecyl sulfate polyacrylamide gel electrophoresis; SOD: Superoxide dismutase; SPSS: Statistical package for the social sciences.

\section{REFERENCES}

1. Shivakumar P, Rani MU, Reddy AG, Anjaneyulu Y. A study on the toxic effects of doxorubicin on the histology of certain organs. Toxicol Int. 2012;19(3):241-4. https://doi.org/10.4103/0971-6580.103656 PMid:23293460 PMCid:PMC3532767.

2. Koti BC, Nagathan S, Vishwanathswamy A, Gadad PC, Thippeswamy A. Cardioprotective effect of Vedic Guard against doxorubicin-induced cardiotoxicity in rats: A biochemical, electrocardiographic, and histopathological study. Pharmacogn Mag. 2013;9(34):176-81. https://doi.org/10.4103/09731296.111287 PMid:23772115 PMCid:PMC3680859.

3. Pandey G, Madhuri S. Some medicinal plants as natural anticancer agents. Pharmacogn Rev. 2009;3(6):259-63.

4. Naiyara A, Abdul E, Ali AA, Ahmed RA. Simavastatin cardioprotective effect in doxorubicin induced cardiotoxicity in rats. J Basic Appl Sci. 2010;6: 29-38.

5. Ayla S, Seckin I, Tanriverdi G, Cengiz M, Eser M, Soner BC, et al. Doxorubicin induced nephrotoxicity: protective effect of nicotinamide. Int J Cell Biol. 2011:9page. doi:10.1155/2011/390238. https://doi. org/10.1155/2011/390238.

6. Prahalathan C, Selvekuma E, VaralakshmiP. Lipoic acid ameliorates adriamycininduced testicular mitochondriopathy. Reprod Toxicol. 2005;20(1):111-6. https://doi.org/10.1016/j.reprotox.2004.12.005 PMid:15808794.

7. Ahmed F, Urooj A, Karim AA. Protective effects of Ficus racemosa stem bark against doxorubucin-induced renal and testicular toxicity. Pharmacogn Mag. 2013;9(34):130-4. https://doi.org/10.4103/0973-1296.111265 PMid:23772108 PMCid:PMC3680852.

8. Shiromwar SS, Chidrawar VR. Combined effects of p-coumaric acid and naringenin against doxorubicin-induced cardiotoxicity in rats. Pharmacogn Mag. 2011;3(3):214-9. https://doi.org/10.4103/0974-8490.85012 PMid:22022172 PMCid:PMC3193624.

9. Berthiaume JM, Wallace KB. Adriamycin-induced oxidative mitochondrial cardiotoxicity. Cell Biol Toxicol. 2007;23(1):15-25. https://doi.org/10.1007/ s10565-006-0140-y PMid:17009097.

10. Zhu C, Xuan X, Che R, Ding G, Zhao M, Bai M, et al. Dysfunction of the $P G C-1 \alpha-m i t o c h o n d r i a$ axis confers adriamycin-induced podocyte injury. Am J Physiol Renal Physiol. 2014;306(12):F1410-17. https://doi.org/10.1152/ ajprenal.00622.2013 PMid:24808537.

11. Wang Z, Liu J, Sun W. Effects of asiaticoside on levels of podocyte cytoskeletal proteins and renal slit diaphragm proteins in adriamycin-induced rat nephropathy. Life Sci. 2013;93(8):352-8. https://doi.org/10.1016/j. Ifs.2013.07.010 PMid:23871990.

12. Zhong F, Wang W, Lee K, He JC, Chen N. Role of C/EBP- $\alpha$ in Adriamycininduced podocyte injury. Sci Rep. 2016;6:33520. doi: 10.1038/ srep33520. https://doi.org/10.1038/srep33520.

13. Perk J, Graham I, De BG. Prevention of cardiovascular disease: new guidelines, new tools, but challenges remain. Heart. 2014;100:675-7. https:// doi.org/10.1136/heartjnl-2014-305650 PMid:24667311.

14. Cai J, Yu X, Zhang B, Zhang H, Fang Y, Liu S, et al. Atorvastatin improves survival of implanted stem cells in a rat model of renal ischemia reperfusion injury. Am J Nephrol. 2014;39(6):466-75. https://doi.org/10.1159/000362623 PMid:24854145.

15. Hasanpour Z, Nasri H, Rafieian-Kopaei M, Ahmadi A, Baradaran A, Nasri P, et al. Paradoxical effects of atorvastatin on renal tubular cells: an experimental investigation. Iran J Kidney Dis. 2015;9(3):215-20. PMid:25957426.

16. Pickering JW, Endre $\mathrm{ZH}$. The definition and detection of acute kidney injury. J Renal Inj Prev. 2014;3:21-5. PMid:25340159.

17. Fassett RG, Robertson IK, Ball MJ, Geraghty DP, Coombes JS. Effects of atorvastatin on biomarkers of inflammation in chronic kidney disease. Clin Nephrol. 2014;81(2):75-85. https://doi.org/10.5414/CN108090 PMid:24321183.

18. Alanazi FK. Pravastatin provides antioxidant activity and protection of erythrocytes loaded primaquine. Int J Med Sci. 2010;7(6):358-65. https://doi. org/10.7150/ijms.7.358.

19. Dursun S, Çuhadar S, Köseoğlu M, Atay A, Aktaş SG. The anti-inflammatory and antioxidant effects of pravastatin and nebivolol in rat aorta. Anadolu Kardiyol Derg. 2014;14(3):229-33. https://doi.org/10.5152/akd.2013.4708 PMid:24936540. 
20. Matsui I, Ito T, Kurihara H, Imai E, Ogihara T, Hori M. Snail, a transcriptional regulator, represses nephrin expression in glomerular epithelial cells of nephritic rats. Lab Invest. 2007;87(3):273-83. https://doi.org/10.1038/ labinvest.3700518 PMid:17260001.

21. Mansouri E, Khorsandi, L, Moaiedi, MZ. Grape seed proanthocyanidin extract improved some of biochemical parameters and antioxidant disturbances of red blood cells in diabetic rats. Iran J Pharm Res. 2015;14(1):329-34. PMid:25561939 PMCid:PMC4277646.

22. Mansouri E, Khorsandi L, Abedi HA. Antioxidant effects of proanthocyanidin from grape seed on hepatic tissue injury in diabetic rats. Iran J Basic Med Sci. 2014;17(6):460-4. PMid:25140209 PMCid:PMC4137947.

23. El-Sheikha AAK, Mohamed A, Morsya MA, Mahmouda MM, Rifaai RA. Protective mechanisms of coenzyme-Q10 mayinvolve up-regulation of testicular P-glycoproteinin doxorubicin-induced toxicity. Environ Toxicol Pharmacol. 2014;37(2):772-81. https://doi.org/10.1016/j.etap.2014.02.010 PMid:24632013.

24. Li C, Yang CW, Park JH, Lim SW, Sun BK, Jung JY, et al. Pravastatin treatment attenuates interstitial inflammation and fibrosis in a rat model of chronic cyclosporine-induced nephropathy. Am J Physiol Renal Physiol. 2004;286(1):F46-F57. https://doi.org/10.1152/ajprenal.00428.2002 PMid:14519596.

25. Kido M, Ando K, Oba S, Fujita T. Renoprotective effect of pravastatin in saltloaded dahl salt-sensitive rats. Hypertens Res. 2005;28(12):1009-15. https:// doi.org/10.1291/hypres.28.1009 PMid:16671341.

26. Browman DT, Hoegg MB, Robbins SM. The SPFH domain-containing proteins: more than lipid raft markers. Trends Cell Biol. 2007;17(8):394-402. https://doi.org/10.1016/j.tcb.2007.06.005 PMid:17766116.
27. Philippe A, Weber S, Esquivel EL, Houbron C, Hamard G, Ratelade J, et al. A missense mutationin podocin leads to early and severe renal disease in mice. Kidney Int. 2008;73(9):1038-47. https://doi.org/10.1038/ki.2008.27 PMid:18288100.

28. Wei P, Grimm PR, Settles DC, Balwanz CR, Padanilam BJ, Sansom SC. Simvastatin reverses podocyte injury but not mesangial expansion in early stage type 2 diabetes mellitus. Ren Fail. 2009;31(6):503-13. https://doi. org/10.1080/08860220902963848 PMid:19839828.

29. Shibata S, Nagase M, Fujita T. Fluvastatin ameliorates podocyte injury in proteinuric rats via modulation of excessive Rho signaling. J Am Soc Nephrol. 2006;17(3):754-64. https://doi.org/10.1681/ASN.2005050571 PMid:16452496.

30. Pavlova V, Sainova I, Alexieva B, Valkova I, Markova T, Nikolova E. Antioxidant effect of aronia melanocarpa extract after doxorubicin treatment. Bulg J Agric Sci. 2014;20(1):188-92.

31. Wu R, Gao JP, Wang HL, Gao Y, Wu Q, Cui XH. Effects of fermented Cordyceps sinensis on oxidative stress in doxorubicin treated rats. Pharmacogn Mag. 2015;11(44):724-31. https://doi.org/10.4103/09731296.165562 PMid:26600716 PMCid:PMC4621640.

32. Haendeler J, Hoffmann J, Zeiher AM, Dimmeler S. Antioxidant effects of statins via S-nitrosylation and activation of thioredoxin in endothelial cells a novel vasculoprotective function of statins. Circulation. 2010;3:134-40.

33. Panonnummal R, Varkey J. Statins induced nephrotoxicity: a dose dependent study in albino rats. Int J Pharm Pharm Sci. 2014;6(11):401-6.

\section{SUMMARY}

- Effects of pravastatin on doxorubicin-induced nephrotoxocity indicated that pravastatin can prevent and cure decreased expression of podocin protein and mRNA in nephrotoxicity group.

- In addition to pravastatin can decrease oxidative stress by increasing of antioxidant enzymes and decreasing of malondialdehyde in the groups that had received doxorubicin.

\section{About Authors}

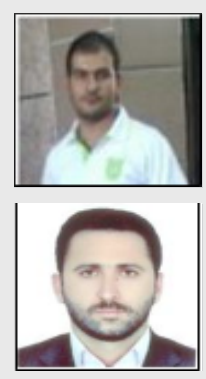

Wesam Kooti: MsC Student of Immunology in Kurdistan University of Medical Science, Sanandaj, Iran.

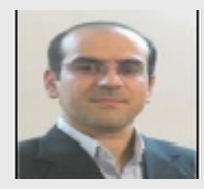

Esrafil Mansouri: Assistant Professor of Histology in Department of Anatomical Sciences, Faculty of Medicine, Ahvaz Jundishapur University of Medical Sciences, Ahvaz, Iran.

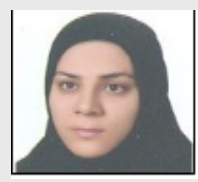

Mohammad-Ali Assarehzadegan: Assistant Professor of Immunology in Department of Immunology, Faculty of Medicine, Ahvaz Jundishapur University of Medical Sciences, Ahvaz, Iran.

Fereshteh Nejad-Dehbashi: PhD Student of Cellular and Molecular Biology of Cellular and Molecular Research Center in Faculty of Medicine, Ahvaz Jundishapur University of Medical Sciences, Ahvaz, Iran.

Cite this article: Kooti W, Mansouri E, Assarehzadegan M, Nejad-Dehbashi F. Effect of Pravastatin on Levels of Filtration Slit Diaphragm Protein and Oxidative Stress in Doxorubicin-Induced Nephrotoxicity. Indian $\mathrm{J}$ of Pharmaceutical Education and Research. 2017;51(1):77-82. 